\title{
Carbon Capture and Usage by MXenes
}

Raul Morales-Salvador, ${ }^{\dagger}$, José D. Gouveia, ${ }^{\star}$, Ángel Morales-García, ${ }^{\dagger}$ Francesc Viñes ${ }^{*} \dagger$ José R. B. Gomes, $\stackrel{+}{*}$ Francesc Illas ${ }^{\dagger}$

${ }^{\dagger}$ Departament de Ciència de Materials i Química Física \& Institut de Química Teòrica i Computacional (IQTCUB), Universitat de Barcelona, c/ Martí i Franquès 1-11, 08028 Barcelona, Spain

$\$$ CICECO - Aveiro Institute of Materials, Department of Chemistry, University of Aveiro, Campus Universitário de Santiago, Aveiro, Portugal

*Corresponding author: Francesc Viñes (francesc.vines@ub.edu)

^ Both authors equally contributed

\section{Index of Contents}

S1. Adsorption landscapes S2

S2. Activity descriptors S7

S3. Reaction steps S9

S4. Reaction profiles S11

S5. Reaction rates S14

S6. Kinetic phase diagrams S18

S7. Oxygen coverage effects 


\section{S1. Adsorption landscapes}

The adsorption landscapes of the $\mathrm{CO}_{2}, \mathrm{CO}$, and $\mathrm{O}$ surface moieties was thoroughly studied. For the $\mathrm{CO}_{2}$ adsorption, the $E_{\text {ads }}^{\mathrm{CO}_{2}}$ values were data-mined and reproduced from previous studies, ${ }^{1-3}$ using the very same $\mathrm{M}_{2} \mathrm{X}$ models and computational set-up, thus exempt from inaccuracies raising from the employed models and calculation type. Table S1 contains a summary of most stable adsorption sites for each moiety, alongside with the site short-definition, while Tables S2-S5 report exhaustive adsorption energy values for $\mathrm{O}$ adatoms, perpendicular and parallel $\mathrm{CO}$ adsorptions, and $\mathrm{CO}_{2}$ adsorption conformations, respectively. Top and side views of the different $\mathrm{O}$ and $\mathrm{CO}$ adsorption minima are shown in Figures S1 and S2, respectively.

Table S1. Adsorption energy, $E_{\text {ads }}$, including ZPE, for $\mathrm{CO}_{2}, \mathrm{CO}$, and $\mathrm{O}$ on each most stable adsorption site on the studied MXenes, alongside with the adsorption conformation notation. $\mathrm{CO}_{2}$ sites were taken from literature. ${ }^{1-3}$ All values are given in $\mathrm{eV}$.

\begin{tabular}{cccccccc}
\hline & $\mathbf{M}$ & $\mathbf{C O}_{\mathbf{2}}$ & $\mathbf{C O}$ & $\mathbf{O}$ & $\mathbf{C O}_{\mathbf{2}}$ & $\begin{array}{c}\mathbf{M}_{\mathbf{2}} \mathbf{C} \\
\mathbf{C O}\end{array}$ & $\mathbf{O}$ \\
\hline \hline $\boldsymbol{d}^{\mathbf{2}}$ & $\mathrm{Ti}$ & $-3.21 / \mathrm{C}_{\mathrm{m}} \mathrm{O}_{\mathrm{x}} \mathrm{O}_{\mathrm{x}}$ & $-3.20 / \mathrm{C}_{\mathrm{m}} \mathrm{O}_{\mathrm{x}}$ & $-8.77 / \mathrm{O}_{\mathrm{m}}$ & $-3.65 / \mathrm{C}_{\mathrm{x}} \mathrm{O}_{\mathrm{m}} \mathrm{O}_{\mathrm{m}}$ & $-3.37 / \mathrm{C}_{\mathrm{x}} \mathrm{O}_{\mathrm{m}}$ & $-8.82 / \mathrm{O}_{\mathrm{m}}$ \\
& $\mathrm{Zr}$ & $-2.97 / \mathrm{C}_{\mathrm{m}} \mathrm{O}_{\mathrm{x}} \mathrm{O}_{\mathrm{x}}$ & $-2.96 / \mathrm{C}_{\mathrm{m}} \mathrm{O}_{\mathrm{b}}$ & $-8.41 / \mathrm{O}_{\mathrm{m}}$ & $-3.12 / \mathrm{C}_{\mathrm{x}} \mathrm{O}_{\mathrm{m}} \mathrm{O}_{\mathrm{m}}$ & $-2.77 / \mathrm{C}_{\mathrm{x}} \mathrm{O}_{\mathrm{m}}$ & $-8.58 / \mathrm{O}_{\mathrm{m}}$ \\
& $\mathrm{Hf}$ & $-3.06 / \mathrm{C}_{\mathrm{m}} \mathrm{O}_{\mathrm{x}} \mathrm{O}_{\mathrm{x}}$ & $-3.09 / \mathrm{C}_{\mathrm{m}} \mathrm{O}_{\mathrm{x}}$ & $-9.02 / \mathrm{O}_{\mathrm{m}}$ & $-3.18 / \mathrm{C}_{\mathrm{x}} \mathrm{O}_{\mathrm{m}} \mathrm{O}_{\mathrm{m}}$ & $-2.99 / \mathrm{C}_{\mathrm{m}} \mathrm{O}_{\mathrm{x}}$ & $-8.90 / \mathrm{O}_{\mathrm{m}}$ \\
\hline $\boldsymbol{d}^{\boldsymbol{3}}$ & $\mathrm{V}$ & $-1.68 / \mathrm{C}_{\mathrm{b}}$ & $-2.39 / \mathrm{C}_{\mathrm{m}} \mathrm{O}_{\mathrm{b}}$ & $-7.78 / \mathrm{O}_{\mathrm{m}}$ & $-2.34 / \mathrm{C}_{\mathrm{x}} \mathrm{O}_{\mathrm{m}} \mathrm{O}_{\mathrm{m}}$ & $-2.90 / \mathrm{C}_{\mathrm{m}} \mathrm{O}_{\mathrm{b}}$ & $-8.07 / \mathrm{O}_{\mathrm{m}}$ \\
& $\mathrm{Nb}$ & $-1.71 / \mathrm{C}_{\mathrm{b}}$ & $-2.39 / \mathrm{C}_{\mathrm{m}} \mathrm{O}_{\mathrm{b}}$ & $-7.83 / \mathrm{O}_{\mathrm{m}}$ & $-2.05 / \mathrm{C}_{\mathrm{m}} \mathrm{O}_{\mathrm{b}}$ & $-2.73 / \mathrm{C}_{\mathrm{m}} \mathrm{O}_{\mathrm{b}}$ & $-8.04 / \mathrm{O}_{\mathrm{m}}$ \\
& $\mathrm{Ta}$ & $-2.31 / \mathrm{C}_{\mathrm{m}} \mathrm{O}_{\mathrm{x}} \mathrm{O}_{\mathrm{x}}$ & $-2.55 / \mathrm{C}_{\mathrm{m}} \mathrm{O}_{\mathrm{b}}$ & $-8.08 / \mathrm{O}_{\mathrm{m}}$ & $-2.35 / \mathrm{C}_{\mathrm{m}} \mathrm{O}_{\mathrm{b}}$ & $-2.65 / \mathrm{C}_{\mathrm{m}} \mathrm{O}_{\mathrm{b}}$ & $-8.18 / \mathrm{O}_{\mathrm{m}}$ \\
\hline $\boldsymbol{d}^{4}$ & $\mathrm{Cr}$ & $-2.33 / \mathrm{C}_{\mathrm{b}} \mathrm{O}_{\mathrm{b}} \mathrm{O}_{\mathrm{b}}$ & $-2.94 / \mathrm{C}_{\mathrm{c}}$ & $-7.75 / \mathrm{O}_{\mathrm{m}}$ & $-1.52 / \mathrm{C}_{\mathrm{m}} \mathrm{O}_{\mathrm{m}} \mathrm{O}_{\mathrm{b}}$ & $-2.54 / \mathrm{C}_{\mathrm{m}} \mathrm{O}_{\mathrm{b}}$ & $-7.46 / \mathrm{O}_{\mathrm{m}}$ \\
& $\mathrm{Mo}$ & $-1.22 / \mathrm{C}_{\mathrm{b}} \mathrm{O}_{\mathrm{b}} \mathrm{O}_{\mathrm{b}}$ & $-2.35 / \mathrm{C}_{\mathrm{c}}$ & $-7.32 / \mathrm{O}_{\mathrm{x}}$ & $-1.62 / \mathrm{C}_{\mathrm{m}} \mathrm{O}_{\mathrm{b}}$ & $-2.43 / \mathrm{C}_{\mathrm{m}} \mathrm{O}_{\mathrm{b}}$ & $-7.03 / \mathrm{O}_{\mathrm{x}}$ \\
& $\mathrm{W}$ & $-2.45 / \mathrm{C}_{\mathrm{m}} \mathrm{O}_{\mathrm{m}} \mathrm{O}_{\mathrm{b}}$ & $-2.41 / \mathrm{C}_{\mathrm{c}}$ & $-7.62 / \mathrm{O}_{\mathrm{m}}$ & $-1.26 / \mathrm{C}_{\mathrm{x}} \mathrm{O}_{\mathrm{m}} \mathrm{O}_{\mathrm{m}}$ & $-2.21 / \mathrm{C}_{\mathrm{c}}$ & $-7.37 / \mathrm{O}_{\mathrm{x}}$ \\
\hline & & & & & & &
\end{tabular}


Table S2. Adsorption energy of $\mathrm{O}$ adatoms, $E_{a d s}^{O}$, including ZPE for all the located minima sites on the studied $\mathrm{M}_{2} \mathrm{X}$ (0001) surfaces. Dashed lines denote cases for which a stable minimum was not found. All values are given in eV.

\begin{tabular}{cccccccc}
\hline & Metal & \multicolumn{3}{c}{$\mathbf{M}_{\mathbf{2}} \mathbf{N}$} & \multicolumn{3}{c}{$\mathbf{M}_{\mathbf{2}} \mathbf{C}$} \\
& & $\mathbf{H}_{\mathbf{m}}$ & $\mathbf{H}_{\mathbf{x}}$ & $\mathbf{T o p}$ & $\mathbf{H}_{\mathbf{m}}$ & $\mathbf{H}_{\mathbf{x}}$ & $\mathbf{T o p}$ \\
\hline \hline $\boldsymbol{d}^{\mathbf{2}}$ & $\mathrm{Ti}$ & -8.77 & -8.41 & -6.40 & -8.82 & -8.53 & - \\
& $\mathrm{Zr}$ & -8.41 & -8.43 & -6.02 & -8.58 & -8.31 & -5.91 \\
& $\mathrm{Hf}$ & -9.02 & -8.65 & -6.07 & -8.90 & -8.54 & - \\
\hline $\boldsymbol{d}^{\mathbf{3}}$ & $\mathrm{V}$ & -7.78 & -7.19 & -6.22 & -8.07 & -7.76 & -6.34 \\
& $\mathrm{Nb}$ & -7.83 & -7.18 & -6.16 & -8.04 & -7.54 & -6.08 \\
& $\mathrm{Ta}$ & -8.08 & -7.55 & -6.46 & -8.18 & -7.60 & -6.01 \\
\hline $\boldsymbol{d}^{\mathbf{4}}$ & $\mathrm{Cr}$ & -7.75 & -7.69 & -6.30 & -7.46 & -7.19 & -6.04 \\
& $\mathrm{Mo}$ & -6.84 & -7.32 & -6.53 & -7.03 & -7.03 & -6.23 \\
& $\mathrm{~W}$ & -6.78 & -7.26 & -7.62 & -6.47 & -7.37 & -5.71 \\
\hline
\end{tabular}

Table S3. Adsorption energies of CO, $E_{a d s}^{C O}$, including ZPE for all the located minima sites having the CO molecule attached perpendicular to the studied $\mathrm{M}_{2} \mathrm{X}(0001)$ surfaces, and being $\mathrm{C}$-connected. Dashed lines denote cases for which a stable perpendicular minimum was not found, normally implying a molecular desorption or its tilting towards a parallel adsorption conformation. All values are given in $\mathrm{eV}$.

\begin{tabular}{cccccccc}
\hline & Metal & \multicolumn{3}{c}{$\mathbf{M}_{\mathbf{2}} \mathbf{N}$} & \multicolumn{3}{c}{$\mathbf{M}_{\mathbf{2}} \mathbf{C}$} \\
& & $\mathbf{H}_{\mathbf{m}}$ & $\mathbf{H}_{\mathbf{x}}$ & $\mathbf{T o p}$ & $\mathbf{H}_{\mathbf{m}}$ & $\mathbf{H}_{\mathbf{x}}$ & $\mathbf{T o p}$ \\
\hline \hline $\boldsymbol{d}^{\mathbf{2}}$ & $\mathrm{Ti}$ & -2.23 & -2.26 & -1.83 & -2.19 & -2.05 & -1.72 \\
& $\mathrm{Zr}$ & -2.00 & -2.02 & -1.56 & -1.88 & -1.70 & -1.37 \\
& $\mathrm{Hf}$ & -2.01 & -2.09 & -1.56 & -1.94 & -1.79 & -1.44 \\
\hline $\boldsymbol{d}^{\mathbf{3}}$ & $\mathrm{V}$ & -1.97 & -1.87 & -2.11 & - & -2.24 & -2.20 \\
& $\mathrm{Nb}$ & -1.86 & -1.81 & -1.94 & -2.09 & -2.13 & -1.90 \\
& $\mathrm{Ta}$ & -1.85 & -1.77 & -2.01 & -1.98 & -1.98 & -1.98 \\
\hline $\boldsymbol{d}^{\mathbf{4}}$ & $\mathrm{Cr}$ & -2.94 & -2.42 & -0.75 & -2.37 & - & -2.31 \\
& $\mathrm{Mo}$ & -1.89 & -1.98 & -2.35 & -2.35 & - & -2.32 \\
& $\mathrm{~W}$ & -1.65 & -1.87 & -2.41 & -1.81 & - & -2.21 \\
\hline
\end{tabular}


Table S4. Adsorption energy of $\mathrm{CO}, E_{\text {ads }}^{C O}$, including ZPE for all the located minima sites having the CO molecule attached parallel to the studied $\mathrm{M}_{2} \mathrm{X}(0001)$ surfaces. Dashed lines denote cases where a stable minimum was not found. All values are given in $\mathrm{eV}$.

\begin{tabular}{cccccccccccccc}
\hline & Site & \multicolumn{2}{c}{$\mathbf{C}_{\mathbf{m}} \mathbf{O}_{\mathbf{b}}$} & \multicolumn{2}{c}{$\mathbf{C}_{\mathbf{x}} \mathbf{O}_{\mathbf{m}}$} & \multicolumn{2}{c}{$\mathbf{C}_{\mathbf{x}} \mathbf{O}_{\mathbf{b}}$} & \multicolumn{2}{c}{$\mathbf{C}_{\mathbf{m}} \mathbf{O}_{\mathbf{x}}$} & \multicolumn{3}{c}{$\mathbf{C}_{\mathbf{m}} \mathbf{O}_{\mathbf{m}}$} & \multicolumn{2}{c}{$\mathbf{C}_{\mathbf{b}} \mathbf{O}_{\mathbf{m}}$} \\
& $\mathbf{M}$ & $\mathbf{M}_{\mathbf{2}} \mathbf{N}$ & $\mathbf{M}_{\mathbf{2}} \mathbf{C}$ & $\mathbf{M}_{\mathbf{2}} \mathbf{N}$ & $\mathbf{M}_{\mathbf{2}} \mathbf{C}$ & $\mathbf{M}_{\mathbf{2}} \mathbf{N}$ & $\mathbf{M}_{\mathbf{2}} \mathbf{C}$ & $\mathbf{M}_{\mathbf{2}} \mathbf{N}$ & $\mathbf{M}_{\mathbf{2}} \mathbf{C}$ & $\mathbf{M}_{\mathbf{2}} \mathbf{N}$ & $\mathbf{M}_{\mathbf{2}} \mathbf{C}$ & $\mathbf{M}_{\mathbf{2}} \mathbf{N}$ & $\mathbf{M}_{\mathbf{2}} \mathbf{C}$ \\
\hline $\boldsymbol{d}^{\mathbf{2}}$ & $\mathrm{Ti}$ & - & - & -3.15 & -3.37 & - & - & -3.20 & -3.25 & - & - & - & - \\
& $\mathrm{Zr}$ & -2.96 & - & -2.85 & -2.77 & -2.86 & - & - & -2.75 & - & - & - & -1.96 \\
& $\mathrm{Hf}$ & - & - & -2.87 & -2.88 & - & - & -3.09 & -2.99 & - & - & - & - \\
\hline $\boldsymbol{d}^{\mathbf{3}}$ & $\mathrm{V}$ & -2.39 & -2.90 & - & - & -2.14 & -2.82 & - & - & - & - & - & - \\
& $\mathrm{Nb}$ & -2.39 & -2.73 & - & - & -1.99 & -2.49 & - & - & - & - & - & - \\
& $\mathrm{Ta}$ & -2.55 & -2.65 & - & - & -1.85 & -2.30 & - & -2.70 & - & - & - & - \\
\hline $\boldsymbol{d}^{4}$ & $\mathrm{Cr}$ & - & -2.54 & - & - & - & -2.34 & - & - & - & - & - & -2.42 \\
& $\mathrm{Mo}$ & - & -2.43 & -2.16 & - & - & -2.11 & - & - & - & - & - & - \\
& $\mathrm{W}$ & - & - & - & - & - & - & - & - & -1.93 & - & -2.28 & -2.02 \\
\hline
\end{tabular}

Table S5. Adsorption energies of $\mathrm{CO}_{2}, E_{\text {ads }}^{\mathrm{CO}_{2}}$, including ZPE for all the gained minima sites of $\mathrm{CO}_{2}$ molecule adsorbed on the studied $\mathrm{M}_{2} \mathrm{X}$ MXenes (0001) surfaces. Dashed lines denote cases where a stable minimum was not found. All values are given in $\mathrm{eV}$.

\begin{tabular}{|c|c|c|c|c|c|c|c|c|c|c|c|c|c|c|c|c|c|}
\hline \multirow{2}{*}{\multicolumn{2}{|c|}{$\begin{array}{c}\text { Site } \\
\text { M }\end{array}$}} & \multicolumn{2}{|c|}{$\mathbf{C}_{\mathrm{b}}$} & \multicolumn{2}{|c|}{$\mathrm{C}_{\mathrm{x}} \mathrm{O}_{\mathrm{b}}$} & \multicolumn{2}{|c|}{$\mathrm{C}_{\mathrm{x}} \mathrm{O}_{\mathrm{m}} \mathrm{O}_{\mathrm{m}}$} & \multicolumn{2}{|c|}{$\mathrm{C}_{\mathrm{m}} \mathrm{O}_{\mathrm{b}}$} & \multicolumn{2}{|c|}{$\mathrm{C}_{\mathrm{m}} \mathrm{O}_{\mathrm{x}} \mathrm{O}_{\mathrm{x}}$} & \multicolumn{2}{|c|}{$\mathbf{C}_{\mathrm{b}} \mathbf{O}_{\mathrm{b}} \mathbf{O}_{\mathrm{b}}$} & \multicolumn{2}{|c|}{$\mathrm{C}_{\mathrm{m}} \mathbf{O}_{\mathrm{m}} \mathbf{O}_{\mathrm{b}}$} & \multicolumn{2}{|c|}{$\mathbf{O}_{\mathrm{b}} \mathbf{O}_{\mathrm{b}}$} \\
\hline & & $\mathbf{M}_{2} \mathbf{N}$ & $\mathbf{M}_{2} \mathbf{C}$ & $\mathbf{M}_{2} \mathbf{N}$ & $\mathbf{M}_{2} \mathbf{C}$ & $\mathbf{M}_{2} \mathbf{N}$ & $\mathbf{M}_{2} \mathbf{C}$ & $\mathbf{M}_{2} \mathrm{~N}$ & $\mathbf{M}_{2} \mathbf{C}$ & $\mathbf{M}_{2} \mathbf{N}$ & $\mathbf{M}_{2} \mathbf{C}$ & $\mathbf{M}_{2} \mathbf{N}$ & $\mathbf{M}_{2} \mathbf{C}$ & $\mathbf{M}_{2} \mathbf{N}$ & $\mathbf{M}_{2} \mathbf{C}$ & $\mathbf{M}_{2} \mathrm{~N}$ & $\mathbf{M}_{2} \mathbf{C}$ \\
\hline \multirow[t]{3}{*}{$\overline{d^{2}}$} & $\mathrm{Ti}$ & - & - & - & -2.83 & -3.21 & -3.65 & - & - & -3.21 & -3.43 & - & - & - & - & - & - \\
\hline & $\mathrm{Zr}$ & - & - & - & - & - & -3.12 & - & - & -2.97 & -2.99 & - & - & - & - & - & - \\
\hline & Hf & -2.37 & - & - & - & - & -3.18 & - & - & -3.06 & -3.17 & - & - & - & - & - & - \\
\hline \multirow[t]{3}{*}{$d^{3}$} & $\mathrm{~V}$ & -1.68 & -2.03 & -1.51 & - & - & -2.34 & -1.65 & -2.25 & - & -2.29 & - & - & - & - & - & - \\
\hline & $\mathrm{Nb}$ & -1.71 & -1.96 & -1.48 & - & - & -1.95 & -1.67 & -2.05 & - & -1.96 & - & - & - & - & - & - \\
\hline & $\mathrm{Ta}$ & -1.89 & -1.86 & - & - & -1.89 & -1.29 & - & -2.35 & -2.31 & -2.35 & - & - & - & - & - & -0.60 \\
\hline \multirow[t]{3}{*}{$d^{4}$} & $\mathrm{Cr}$ & -2.30 & - & - & - & - & - & - & - & - & - & -2.33 & - & - & -1.52 & - & - \\
\hline & Mo & -1.22 & -1.62 & - & -1.47 & - & - & -0.91 & -1.62 & - & - & -1.21 & - & - & - & - & - \\
\hline & W & -1.08 & -1.11 & - & - & -1.63 & -1.26 & - & - & - & - & - & - & -2.45 & - & - & - \\
\hline
\end{tabular}


Figure S1. Obtained adsorption sites for O adatoms on the explored MXene (0001) surfaces. Color code for MXene spheres is: yellow, $\mathrm{X}$ atoms; dark blue, topmost $\mathrm{M}$ atoms; light blue, bottommost $\mathrm{M}$ atoms. Red spheres denote the adsorbed $\mathrm{O}$ atoms.

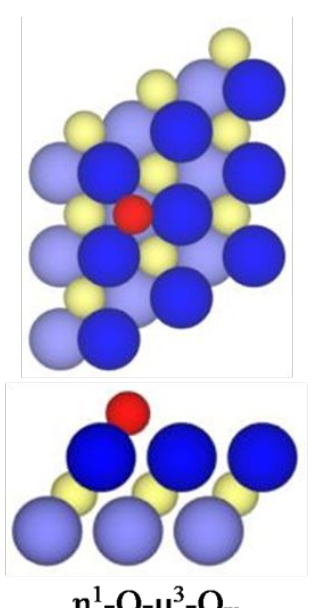

$\eta^{1}-O-\mu^{3}-O_{m}$
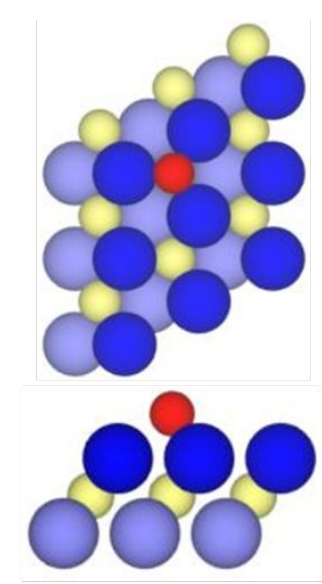

$\eta^{1}-O-\mu^{3}-O_{x}$
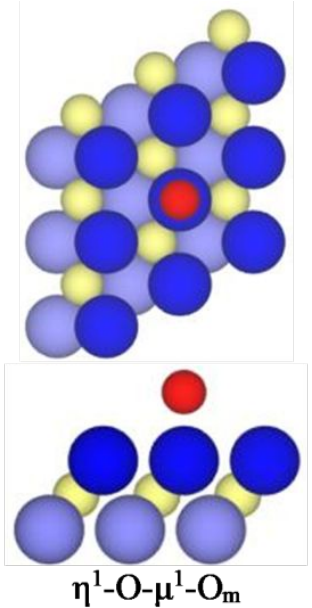
Figure S2. Obtained adsorption sites for CO molecules on the explored MXene (0001) surfaces. Color code for MXene as in Figure S1 while brown and red spheres denote C and $\mathrm{O}$ atoms, respectively.
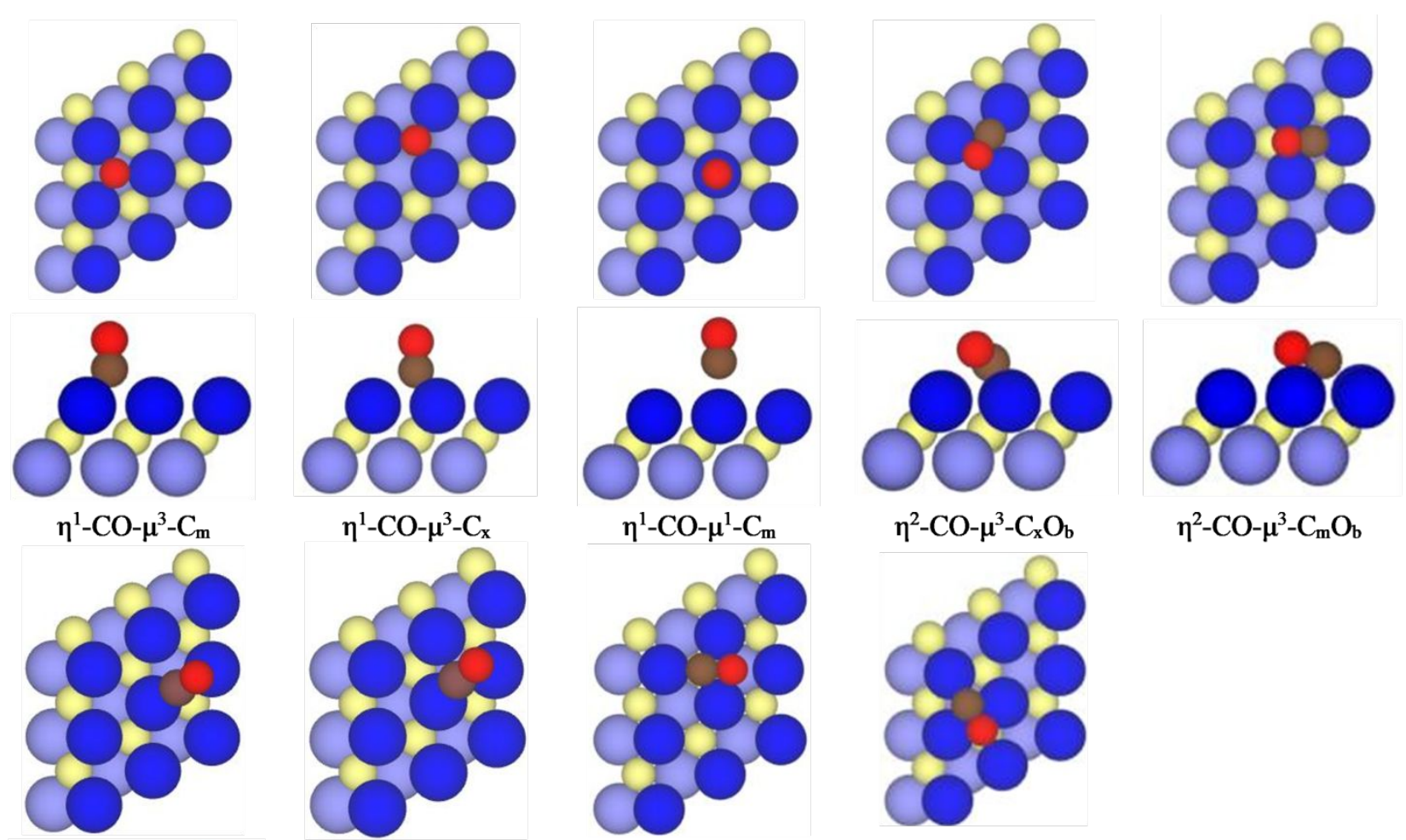

$\eta^{1}-\mathrm{CO}-\mu^{3}-\mathrm{C}_{\mathrm{x}}$
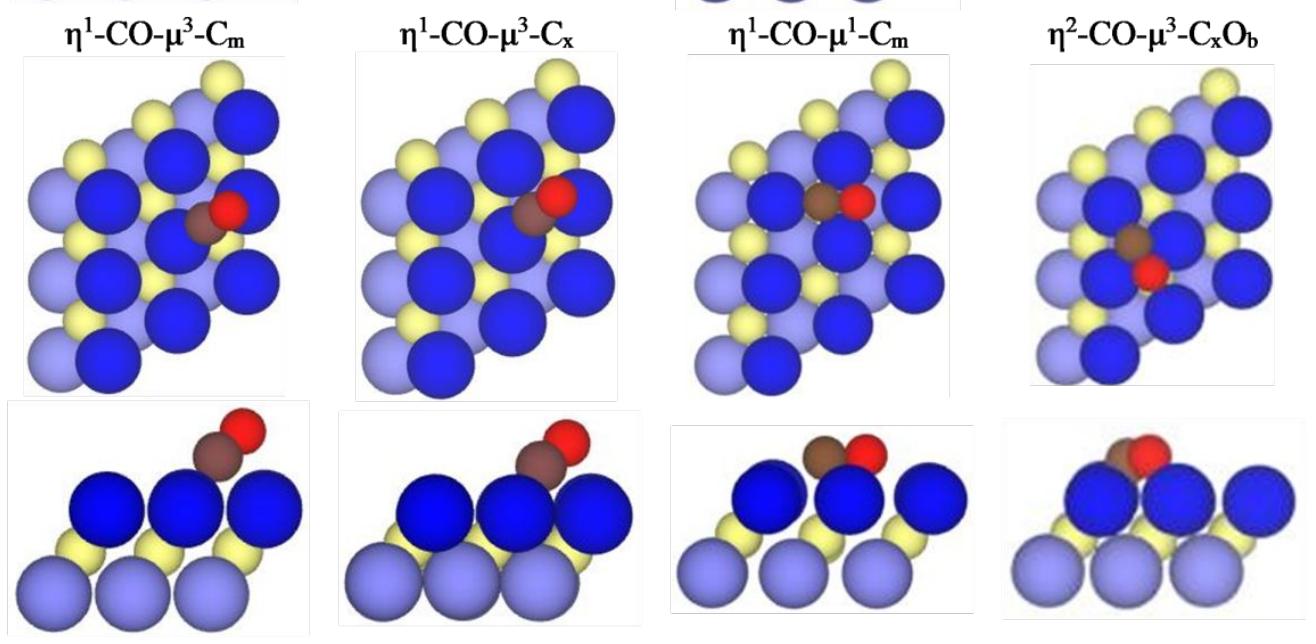

$\eta^{2}-\mathrm{CO}-\mu^{2}-\mathrm{C}_{\mathrm{b}} \mathrm{O}_{\mathrm{m}}$

$\eta^{2}-\mathrm{CO}-\mu^{2}-\mathrm{C}_{\mathrm{m}} \mathrm{O}_{\mathrm{m}}$

$\eta^{2}-\mathrm{CO}-\mu^{4}-\mathrm{C}_{\mathrm{x}} \mathrm{O}_{\mathrm{m}}$

$\eta^{2}-\mathrm{CO}-\mu^{4}-\mathrm{C}_{\mathrm{m}} \mathrm{O}_{\mathrm{x}}$ 


\section{S2. Activity descriptors}

The magnitude of the adsorption of $\mathrm{CO}_{2}, \mathrm{CO}$, and $\mathrm{O}$ surface moieties on the studied $\mathrm{M}_{2} \mathrm{X}$ MXenes (0001) surfaces has been assessed based on surface descriptors, such as the $d$-band center, $\varepsilon_{\mathrm{d}}$, proposed by Hammer and Nørskov, ${ }^{4}$ and the $\mathrm{M} \rightarrow \mathrm{X}$ charge transfer, evaluated on the surface $\mathrm{M}$ atoms charge, $\Delta \mathrm{Q}_{\mathrm{m}}$, through a Bader topological analysis of the electron density. ${ }^{5}$ This analysis of descripting variables is similar to that carried out on O-terminated MXenes on the electrocatalysis of hydrogen evolution reaction, yet considering the $\mathrm{O}$ functional group charge and $p$-band center, $\varepsilon_{\mathrm{p}}{ }^{6}$ The procedure followed to obtain the $d$-band centers is the same as the one found in Vega et al., ${ }^{7}$ using 1000 points to evaluate the projected density of states in a wide enough energy region, containing both the $d$-band initial energy, $E_{\mathrm{i}}$, and its final energy, $E_{\mathrm{f}}$, the latter defined as the energy corresponding to a surface metal $d^{10}$ configuration; for more details of such a standardized procedure, we refer to the literature. ${ }^{7}$ The computed $\Delta \mathrm{Q}_{\mathrm{m}}$ and $\varepsilon_{\mathrm{d}}$ values are encompassed in Table $\mathrm{S} 6$, while the graphical trends of $\mathrm{CO}_{2}, \mathrm{CO}$, and $\mathrm{O}$ adsorption energies versus $\Delta \mathrm{Q}_{\mathrm{m}}$ and $\varepsilon_{\mathrm{d}}$ are shown in Figures 2 and 3 of the main text, respectively. Their linear regression adjustment values of slope, $b$, intercept, $a$, and regression coefficient, $R$, are given in Table S7. 
Table S6. Calculated Bader charges, $\Delta \mathrm{Q}_{\mathrm{m}}$, and $d$-band centers values, $\varepsilon_{\mathrm{d}}$, for the different studied 18 pristine carbide and nitride MXene (0001) surfaces. Charges are given in $e$, and $d$-band centers in $\mathrm{eV}$.

\begin{tabular}{cccccc}
\hline & Metal & \multicolumn{2}{c}{$\mathbf{M}_{\mathbf{2}} \mathbf{N}$} & \multicolumn{2}{c}{$\mathbf{M}_{\mathbf{2}} \mathbf{C}$} \\
& & $\boldsymbol{\Delta} \boldsymbol{Q}_{\mathbf{m}}$ & $\mathcal{E}_{\mathbf{d}}$ & $\boldsymbol{\Delta} \boldsymbol{Q}_{\mathbf{m}}$ & $\boldsymbol{\varepsilon}_{\mathbf{d}}$ \\
\hline \hline $\boldsymbol{d}^{\mathbf{2}}$ & $\mathrm{Ti}$ & 1.05 & 3.54 & 1.16 & 4.06 \\
& $\mathrm{Zr}$ & 0.96 & 2.82 & 1.07 & 3.47 \\
& $\mathrm{Hf}$ & 1.07 & 3.02 & 1.24 & 3.74 \\
\hline $\boldsymbol{d}^{\boldsymbol{3}}$ & $\mathrm{V}$ & 0.92 & 2.48 & 0.94 & 2.54 \\
& $\mathrm{Nb}$ & 0.90 & 0.00 & 0.95 & 0.32 \\
& $\mathrm{Ta}$ & 0.99 & 1.38 & 1.09 & 1.88 \\
\hline $\boldsymbol{d}^{4}$ & $\mathrm{Cr}$ & 0.71 & -0.58 & 0.83 & -0.72 \\
& $\mathrm{Mo}$ & 0.66 & -0.80 & 0.80 & -0.72 \\
& $\mathrm{~W}$ & 0.73 & 0.41 & 0.71 & 0.91 \\
\hline
\end{tabular}

Table S7. Linear regression parameters of $E_{a d s}^{S}=a \cdot D+b$, where $D$ are the employed descriptors, $\Delta \mathrm{Q}_{\mathrm{m}}$ or $\varepsilon_{\mathrm{d}}$, as listed in Table S6, and $E_{a d s}^{S}$ the adsorption energies of the $S$ species, $\mathrm{CO}_{2}, \mathrm{CO}$, or $\mathrm{O}$, as listed in Table $\mathrm{S} 1$. The $a$ values are the linear regression slopes, while $b$ are the intercepts, of the linear adjustments shown in Figures 2 and 3 . The regression coefficients, $R$, are also provided.

\begin{tabular}{ccccccc}
\hline & \multicolumn{3}{c}{$\Delta \boldsymbol{Q}_{\mathbf{m}}$} & \multicolumn{3}{c}{$\boldsymbol{\varepsilon}_{\mathrm{d}}$} \\
& $\boldsymbol{a}$ & $\boldsymbol{b}$ & $\mathbf{R}$ & $\boldsymbol{a}$ & $\boldsymbol{b}$ & $\mathbf{R}$ \\
\hline \hline $\mathbf{C O}_{2}$ & -3.4 & 0.80 & 0.77 & -0.30 & -1.89 & 0.69 \\
$\mathbf{C O}$ & -1.3 & -1.5 & 0.66 & -0.13 & -2.51 & 0.68 \\
$\mathbf{O}$ & -3.1 & -5.2 & 0.88 & -0.30 & -7.59 & 0.88 \\
\hline
\end{tabular}




\section{S3. Reaction steps}

The $\mathrm{CO}_{2} *$ dissociation energetic values, including the dissociation energy change, $\Delta E_{\mathrm{r}}$, and energy barrier, $E_{\mathrm{b}}^{\mathrm{dis}}$, are found in Table 1 of the main text and discussed there. There it appears the more difficult $\mathrm{CO}^{*}$ and $\mathrm{O}^{*}$ recombination, with very large $E_{\mathrm{b}}^{\mathrm{rec}}$ energy barriers given the exothermicity of the $\mathrm{CO}_{2}{ }^{*}$ dissociation, see $\Delta E_{\mathrm{r}}$ values. The resulting $\mathrm{CO}^{*}$ and $\mathrm{O}^{*}$ moieties are co-adsorbed after the $\mathrm{CO} 2$ breakage, with lateral repulsions, which thermodynamically favor their diffusion to more distant sites, see diffusion energy changes, $\Delta E_{\mathrm{d}}$, ranging from $-0.30\left(\mathrm{Hf}_{2} \mathrm{~N}\right.$ and $\left.\mathrm{Ta}_{2} \mathrm{C}\right)$ to $-1.63 \mathrm{eV}$ $\left(\mathrm{Cr}_{2} \mathrm{C}\right)$ in Table S8. The corresponding diffusion energy barriers, $E_{b}^{\text {dif }}$, range from $0.20\left(\mathrm{Ti}_{2} \mathrm{C}\right)$ to 1.06 $\mathrm{eV}\left(\mathrm{Ta}_{2} \mathrm{C}\right)$, implying, in cases like the latter, a certain steadiness of the reaction moieties upon breakage. In any case the diffusion is energetically preferable, with which implies that the $\mathrm{CO}^{*}$ and O* approaching step energy barriers, $E_{b}^{a p r}$, are larger by the $\Delta E_{\mathrm{d}}$ amounts.

Notice that the $\mathrm{CO}_{2}$ adsorption data and transition state structures may be useful for other processes, e.g. in the electrocatalytic reduction of $\mathrm{CO}_{2}$. There, the chemical steps are of similar nature to the present ones, although one should evaluate the $\mathrm{M}_{2} \mathrm{X}(0001)$ surface composition at the reactive conditions through the Pourbaix diagrams, and account for solvation and electrolyte effects as well. In any case, the $\mathrm{CO}_{2}$ electroreduction steps and associated transition states would benefit from the application of a negative overpotential in the $\mathrm{CO}_{2}$ dissociation process. ${ }^{8}$ 
Table S8. Summary of $\Delta E_{\mathrm{d}}, E_{b}^{\text {dif }}$, and $E_{b}^{a p r}$ values, including ZPE, for the CO* and $\mathrm{O}^{*}$ separating, diffusing and the approaching diffusion processes, for each studied MXene (0001) surface. All values are given in eV.

\begin{tabular}{|c|c|c|c|c|c|c|c|}
\hline & \multirow[t]{2}{*}{$\mathbf{M}$} & \multicolumn{4}{|c|}{$\mathbf{M}_{2} \mathbf{N}$} & \multicolumn{2}{|l|}{$\mathbf{M}_{2} \mathbf{C}$} \\
\hline & & $\Delta E_{\mathrm{d}}$ & $E_{b}^{d i f}$ & $E_{b}^{a p r}$ & $\Delta E_{\mathrm{d}}$ & $E_{b}^{d i f}$ & $E_{b}^{a p r}$ \\
\hline \multirow[t]{3}{*}{$\overline{d^{2}}$} & $\mathrm{Ti}$ & $-0.49 / \mathrm{C}_{\mathrm{m}} \mathrm{O}_{\mathrm{x}} \mathrm{O}_{\mathrm{x}}$ & 0.52 & 1.01 & $-0.79 / \mathrm{C}_{\mathrm{x}} \mathrm{O}_{\mathrm{m}} \mathrm{O}_{\mathrm{m}}$ & 0.20 & 0.99 \\
\hline & $\mathrm{Zr}$ & $-0.32 / \mathrm{C}_{\mathrm{m}} \mathrm{O}_{\mathrm{x}} \mathrm{O}_{\mathrm{x}}$ & 0.57 & 0.89 & $-0.80 / \mathrm{C}_{\mathrm{x}} \mathrm{O}_{\mathrm{m}} \mathrm{O}_{\mathrm{m}}$ & 0.34 & 1.14 \\
\hline & $\mathrm{Hf}$ & $-0.30 / \mathrm{C}_{\mathrm{m}} \mathrm{O}_{\mathrm{x}} \mathrm{O}_{\mathrm{x}}$ & 0.75 & 1.05 & $-0.75 / \mathrm{C}_{\mathrm{x}} \mathrm{O}_{\mathrm{m}} \mathrm{O}_{\mathrm{m}}$ & 0.45 & 1.20 \\
\hline \multirow[t]{3}{*}{$d^{3}$} & $\mathrm{~V}$ & $-0.44 / C_{b}$ & 0.55 & 0.99 & $-0.62 / \mathrm{C}_{\mathrm{x}} \mathrm{O}_{\mathrm{m}} \mathrm{O}_{\mathrm{m}}$ & 0.66 & 1.28 \\
\hline & $\mathrm{Nb}$ & $-0.46 / C_{b}$ & 0.66 & 1.12 & $-0.37 / \mathrm{C}_{\mathrm{m}} \mathrm{O}_{\mathrm{b}}$ & 0.53 & 0.90 \\
\hline & $\mathrm{Ta}$ & $-0.50 / \mathrm{C}_{\mathrm{m}} \mathrm{O}_{\mathrm{x}} \mathrm{O}_{\mathrm{x}}$ & 0.54 & 1.04 & $-0.30 / \mathrm{C}_{\mathrm{m}} \mathrm{O}_{\mathrm{b}}$ & 1.06 & 1.36 \\
\hline \multirow[t]{3}{*}{$d^{4}$} & $\mathrm{Cr}$ & $-1.10 / \mathrm{C}_{b} \mathrm{O}_{b} \mathrm{O}_{b}$ & 0.25 & 1.35 & $-1.63 / \mathrm{C}_{\mathrm{b}} \mathrm{O}_{\mathrm{b}} \mathrm{O}_{\mathrm{b}}$ & 0.22 & 1.85 \\
\hline & Mo & $-0.69 / \mathrm{C}_{b} \mathrm{O}_{b} \mathrm{O}_{b}$ & 0.92 & 1.61 & $-0.41 / \mathrm{C}_{\mathrm{m}} \mathrm{O}_{\mathrm{b}}$ & 0.54 & 0.95 \\
\hline & W & $-1.30 / \mathrm{C}_{\mathrm{m}} \mathrm{O}_{\mathrm{m}} \mathrm{O}_{\mathrm{b}}$ & 0.82 & 2.12 & $-0.49 / \mathrm{C}_{\mathrm{x}} \mathrm{O}_{\mathrm{m}} \mathrm{O}_{\mathrm{m}}$ & 0.35 & 0.84 \\
\hline
\end{tabular}




\section{S4. Reaction profiles}

Once each reaction step has been evaluated, the reaction energy profiles can be drawn. Figure S3 shows the energetic definitions for each step, while Figures S4 and S5 show the reaction energy profiles for carbide- and nitride-based MXenes, respectively, as built from the data listed in Tables S1 and S8, and Table 1 of the manuscript.

Figure S3. Reaction profile energetic definitions for the gas phase $\mathrm{CO}_{2(\mathrm{~g})}$ conversion into gas phase $\mathrm{CO}_{(\mathrm{g})}$ while leaving adsorbed $\mathrm{O}^{*}$ on the explored $\mathrm{M}_{2} \mathrm{X}(0001)$ surfaces.

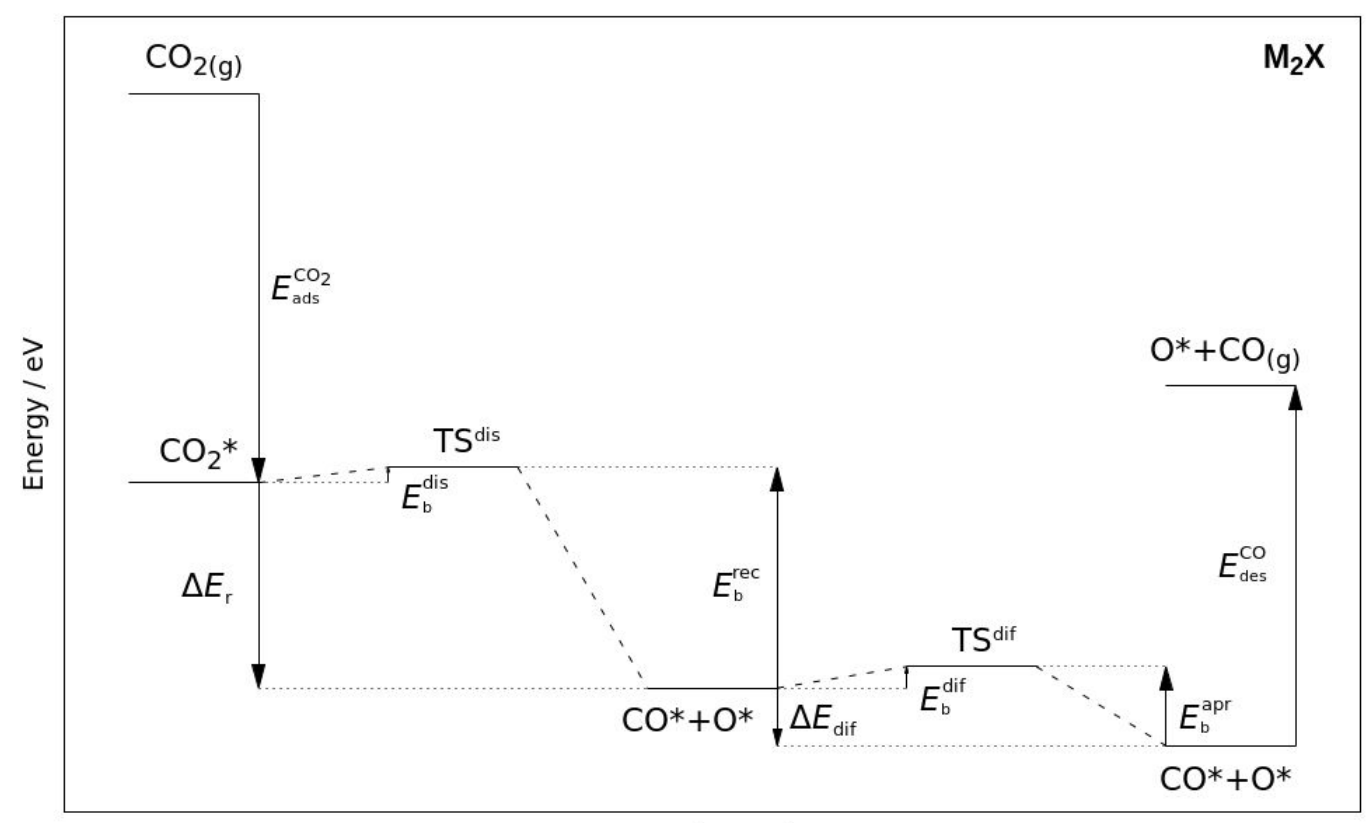

Reaction Path 
Figure S4. Computed reaction energy profiles on the carbide $\mathrm{M}_{2} \mathrm{X}(0001)$ surfaces.

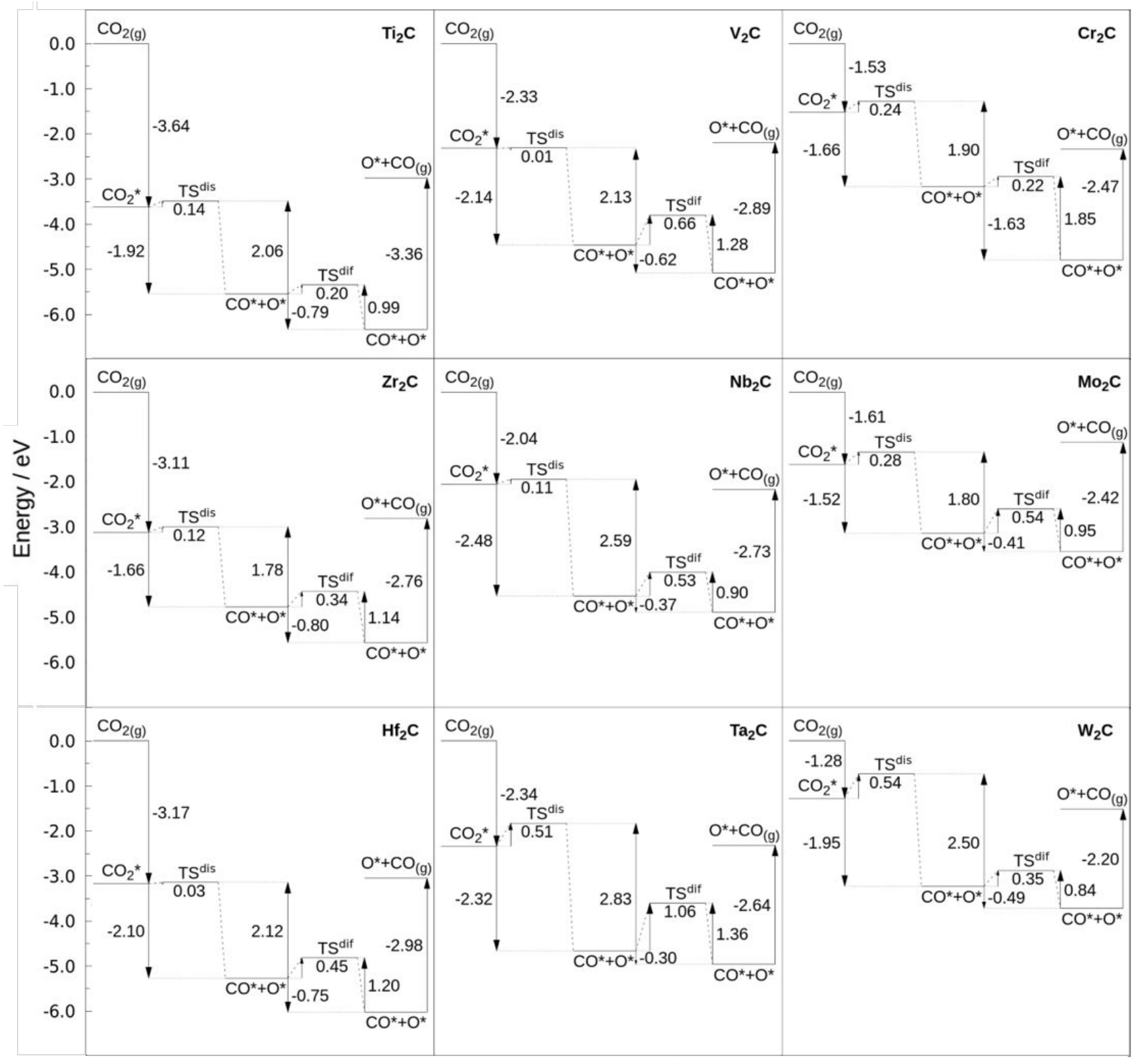

Reaction Path 
Figure S5. Computed reaction energy profiles on the nitride $\mathrm{M}_{2} \mathrm{X}(0001)$ surfaces.

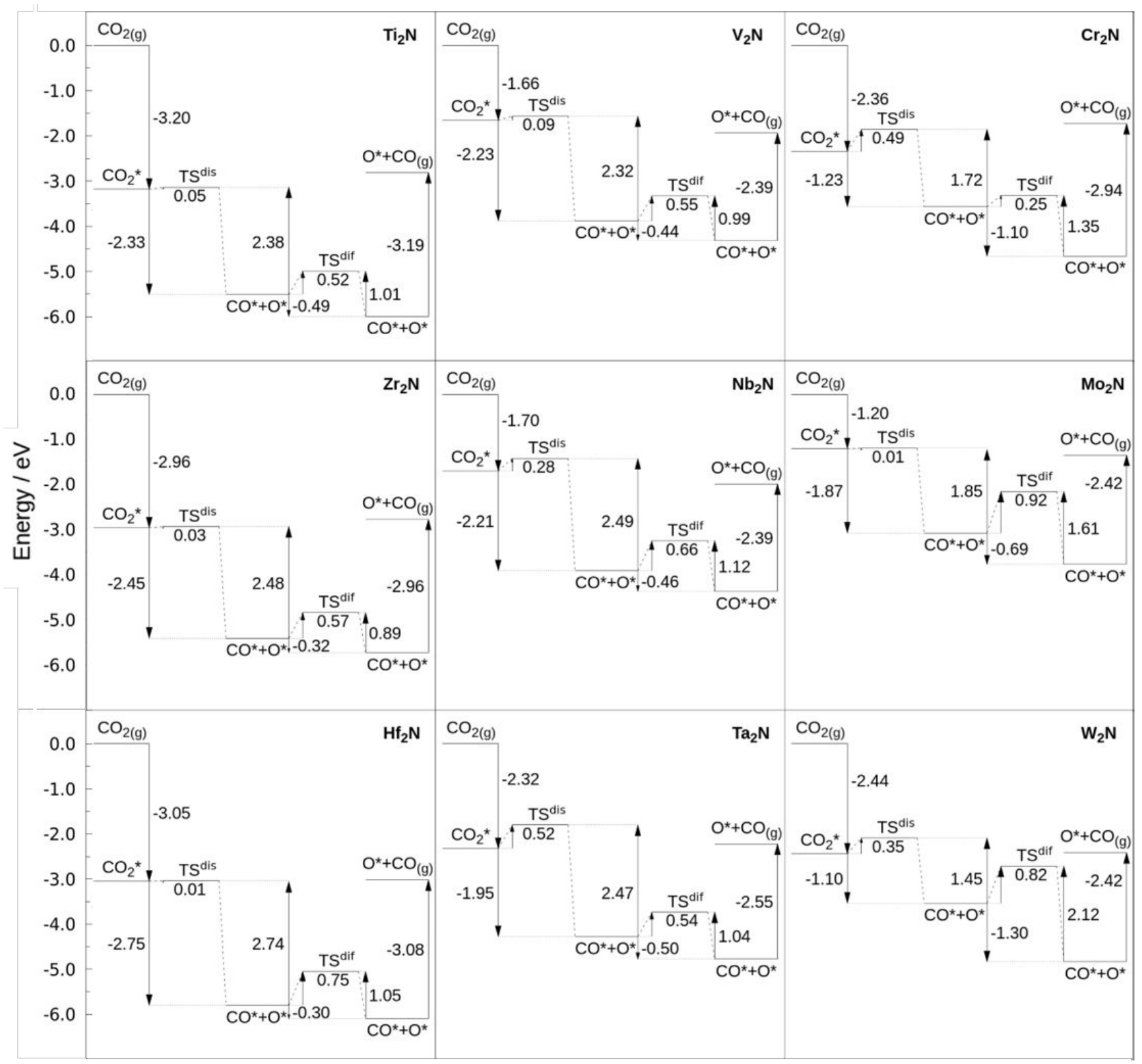

Reaction Path 


\section{S5. Reaction rates}

In this section, the rates for the different reaction processes are estimated. On the one hand, the $\mathrm{CO}_{2}$ adsorption rates were obtained assuming it to be a non-activated process. Within this meaningful choice, the adsorption rate $r_{\mathrm{ads}}$ can be calculated from collision theory or the well-known HerzKnudsen formula, ${ }^{9}$

$$
r_{\mathrm{ads}}=\frac{S_{0} p_{\mathrm{CO}_{2}} \cdot A}{\sqrt{2 \pi \cdot m_{\mathrm{CO}_{2}} \cdot k_{B} \cdot T}}
$$

where $S_{0}$ is the initial $\mathrm{CO}_{2}$ sticking coefficient, $p_{\mathrm{CO}_{2}}$ the $\mathrm{CO}_{2}$ partial pressure in contact to the surface, $T$ is the temperature, $k_{\mathrm{B}}$ the Boltzmann constant, $A$ stands for the area of an active adsorption site, and $m_{\mathrm{CO}_{2}}$ corresponds to the mass of the $\mathrm{CO}_{2}$ molecule. A conservative value of $S_{0}=0.40$ was selected for $\mathrm{CO}_{2}$, as initial sticking coefficients in the range of $0.43-0.73$ were found for $\mathrm{CO}_{2}$ on clean metal surfaces. ${ }^{10}$ Such a value also permits the direct comparison with previous studies on $\mathrm{CO}_{2}$ capture and storage evaluated on transition metal carbides and two-dimensional MXenes. ${ }^{1,2,11}$ Note that an equal adsorption probability is assumed for all sites, and therefore, $A$ is approached as the supercell area of each surface divided by the total number of adsorption sites it contains. In the rate evaluation as a function of $T$ and $p_{\mathrm{CO}_{2}}$, see Figure $\mathrm{S} 6$, three different pressure values representative of different conditions of interest were selected to evaluate $r_{\mathrm{ads}}$ : $i$ ) the current atmospheric partial pressure of $\mathrm{CO}_{2}, p_{\mathrm{CO}_{2}}=40 \mathrm{~Pa} ;{ }^{12}$ ii) a partial pressure of $p_{\mathrm{CO}_{2}}=0.15$ bar $\left(15 \cdot 10^{3} \mathrm{~Pa}\right),{ }^{13}$ which is a reference value for post-combustion exhaust gases, ${ }^{14}$ and iii) a partial pressure of $p_{\mathrm{CO}_{2}}=1.0$ bar $\left(10^{5}\right.$ $\mathrm{Pa}$ ), corresponding to a reference for pure $\mathrm{CO}_{2}$ stream generation from a Carbon Capture and Storage (CCS) system, usable, e.g. as food grade $\mathrm{CO}_{2} \cdot{ }^{15}$

On the other hand, the desorption rate, $r_{\mathrm{des}}$, has been estimated from Transition State Theory (TST) so that the desorption rate $r_{\text {des }}$ is given by

$$
r_{\mathrm{des}}=\frac{k_{B} \cdot T}{h} \cdot \frac{q_{\mathrm{rrans}, 2 \mathrm{D}}^{\mathrm{gas}} \cdot q_{\mathrm{lot}}^{\mathrm{gas}} \cdot q_{\mathrm{vin}}^{\mathrm{gas}}}{q_{\mathrm{vib}}^{\mathrm{dib}}} \exp \left(\frac{E_{\text {des }}}{k_{\mathrm{B}} \cdot T}\right)
$$

where $E_{\mathrm{des}}=-E_{\mathrm{ads}}$; in this case, for $\mathrm{CO}_{2}$, and by this implying that the transition state is supposed to be located infinitely close to the desorption final state. Notice that ZPE corrected $E_{\text {ads }}^{\mathrm{CO}_{2}}$ values of Table S5 can be used, since this is not double-counted in the vibrational partitions functions, see below. The $q$ terms are the partition functions, accounting for the vibrations only in the $\mathrm{CO}_{2}$ adsorbed case found in the denominator, $q_{\mathrm{vib}}^{\text {ads }}$, where all degrees of freedom are considered as vibrations since molecular translations and rotations become frustrated through interaction with the substrate, effectively being converted into vibrations. For the transition state in the numerator, a two- 
dimensional (2D) transition state model is assumed, extended over the $\mathrm{M}_{2} \mathrm{X}(0001)$ surface. In such a model, the $\mathrm{CO}_{2}$ molecule retains translation parallel to the surface, and so a translational partition function, $q_{\text {trans,2D }}^{\text {gas }}$, aside from free rotation, $q_{\text {rot }}^{\text {gas }}$, and the molecular vibrational partition function, $q_{\text {vib }}^{\text {gas }}$ . Such partition functions can be estimated as

$$
\begin{gathered}
q_{\text {trans,2D }}^{\text {gas }}=A \cdot \frac{2 \pi \cdot m_{\mathrm{CO}_{2}} \cdot k_{\mathrm{B}} \cdot T}{h^{2}} \\
q_{\mathrm{vib}}^{\text {ads } / \text { gas }}=\prod_{i} \frac{1}{1-\exp \left(-\frac{h \cdot v_{i}}{k_{\mathrm{B}} \cdot T}\right)} \\
q_{\mathrm{rot}}^{\text {gas }}=\frac{T}{2 \cdot T_{\mathrm{rot}}}
\end{gathered}
$$

where $h$ is the Planck constant and $T_{\text {rot }}$ is the $\mathrm{CO}_{2}$ rotational temperature, multiplied by 2 being the $\mathrm{CO}_{2}$ symmetry number. The $\mathrm{CO}_{2} T_{\text {rot }}$ value is taken from the literature, being $0.561 \mathrm{~K} .{ }^{16}$ Aside, the $v_{\mathrm{i}}$ is the harmonic vibrational frequency of each normal mode as predicted from present DFT calculations, either for the $\mathrm{CO}_{2}$ molecule isolated in vacuum or when adsorbed, accounting then for $3 N-5$ or $3 N$ vibrations, respectively, where $N$ is the number of atoms of $\mathrm{CO}_{2}$.

In the case of $\mathrm{CO}$ adsorption and desorption rates, notice that the same mathematical framework is used, yet employing the $m_{\mathrm{CO}}$ mass of CO, a sticking coefficient $S_{0}=0.80$, also conservative compared to $S_{0}$ values on transition metals as found in the literature, ${ }^{17-20}$ which are of $\sim 0.95$, and using the $\mathrm{CO}$ partial pressure, $p_{\mathrm{CO}}$. For such a molecule, the $A$ also depends on the adsorption conformation and strength, as shown in Table $\mathrm{S} 1$. Finally, the $T_{\text {rot }}$ value of $2.78 \mathrm{~K}$, as taken from literature, ${ }^{16}$ and a symmetry number of one have been used.

The other reaction steps rates, $r_{\mathrm{i}}$, including $\mathrm{CO}_{2}$ dissociation, $r_{\text {dis }}, \mathrm{CO}$ and $\mathrm{O}$ recombination, $r_{\text {rec}}$, as well as $\mathrm{CO}$ or $\mathrm{O}$ diffusions far away, $r_{\mathrm{dif}}$, as well as approaching diffusions, $r_{\mathrm{apr}}$, have been gained within TST. Thus, $r_{\text {dis }}$ has been estimated as

$$
r_{\text {dis }}=\frac{k_{B} \cdot T}{h} \cdot \frac{q_{\mathrm{vib}}^{\mathrm{TS} \text { dis }}}{q_{\mathrm{vib}}^{C O_{2}} \text {, ads }} \exp \left(\frac{-E_{b}^{d i s}}{k_{\mathrm{B}} \cdot T}\right)
$$

where $q_{\text {vib }}^{\text {TS,dis }}$ is the vibrational partition function of the obtained TS along the dissociation path; notice that here the imaginary vibrational frequency is not accounted for, and thus, $3 N-1$ vibrational frequencies are used. Aside, the $q_{\mathrm{vib}}^{\mathrm{CO}_{2} \text {, ads }}$ is the aforementioned vibrational partition function of the adsorbed state. Similarly, the other reaction rates are defined as

$$
\begin{aligned}
& r_{\text {rec }}=\frac{k_{B} \cdot T}{h} \cdot \frac{q_{\mathrm{vib}}^{\mathrm{TS} S \mathrm{dis}}}{q_{\mathrm{vib}}^{C O \text {, ads }} \cdot q_{\mathrm{vib}}^{O_{\text {ad }}}} \exp \left(\frac{-E_{b}^{r e c}}{k_{\mathrm{B}} \cdot T}\right) \\
& r_{\mathrm{dif}}=\frac{k_{B} \cdot T}{h} \cdot \frac{q_{\mathrm{vib}}^{\mathrm{TS}, \mathrm{dif}}}{q_{\mathrm{vib}}^{C O} \text { ads }} \cdot q_{\mathrm{vib}}^{O_{\text {vib }}} \exp \left(\frac{-E_{b}^{\text {dif }}}{k_{\mathrm{B}} \cdot T}\right)
\end{aligned}
$$




$$
r_{\mathrm{apr}}=\frac{k_{B} \cdot T}{h} \cdot \frac{q_{\mathrm{vib}}^{\mathrm{TS}, \mathrm{dif}}}{q_{\mathrm{vib}}^{C \text {, far }} \cdot q_{\mathrm{vib}}^{O \text { far }}} \exp \left(\frac{-E_{b}^{a p r}}{k_{\mathrm{B}} \cdot T}\right)
$$

where $q_{\mathrm{vib}}^{C O}$, ads and $q_{\mathrm{vib}}^{O}$ ads are the vibrational frequencies of the $\mathrm{CO}^{*}$ and $\mathrm{O}^{*}$ species when nearby coadsorbed, as resulting from the $\mathrm{CO}_{2}$ splitting, while $q_{\mathrm{vib}}^{C O}$, far and $q_{\mathrm{vib}}^{O_{1}}$ far are the vibrational frequencies of the same $\mathrm{CO}^{*}$ and $\mathrm{O}^{*}$ moieties when adsorbed far from each other, after the diffusion process. The energy barriers are those listed in Tables S8 and S9.

The above estimations permit to evaluate the different reaction steps rates as a function of temperature, or $\mathrm{CO}$ or $\mathrm{CO}_{2}$ partial pressures. Figure $\mathrm{S} 6$ shows the limiting cases of $\mathrm{Ti}_{2} \mathrm{C}$ and $\mathrm{Cr}_{2} \mathrm{~N}$. Notice that the adsorption rates for $\mathrm{CO}_{2}$ and $\mathrm{CO}$ at the different partial pressures essentially coincide, and so, only the one of $\mathrm{CO}_{2}$ is shown in Figure S6. Further than this, the results clearly show that dissociation rates are larger than the desorption ones for the full conditions range, implying straightforward $\mathrm{CO}_{2}$ dissociation upon adsorption, and, concomitantly, hampering $\mathrm{CO}+\mathrm{O}$ recombination. 
Figure S6. Evaluation of reaction rates with temperature for the $\mathrm{Ti}_{2} \mathrm{C}$ (top) and $\mathrm{Mo}_{2} \mathrm{~N}$ (bottom) limiting situations. The adsorption rates for $\mathrm{CO}_{2}$ correspond to partial pressures of $40 \mathrm{~Pa}$ (air), $15 \cdot 10^{3} \mathrm{~Pa}$ (exhaust), and $10^{5} \mathrm{~Pa}$ (desorption).

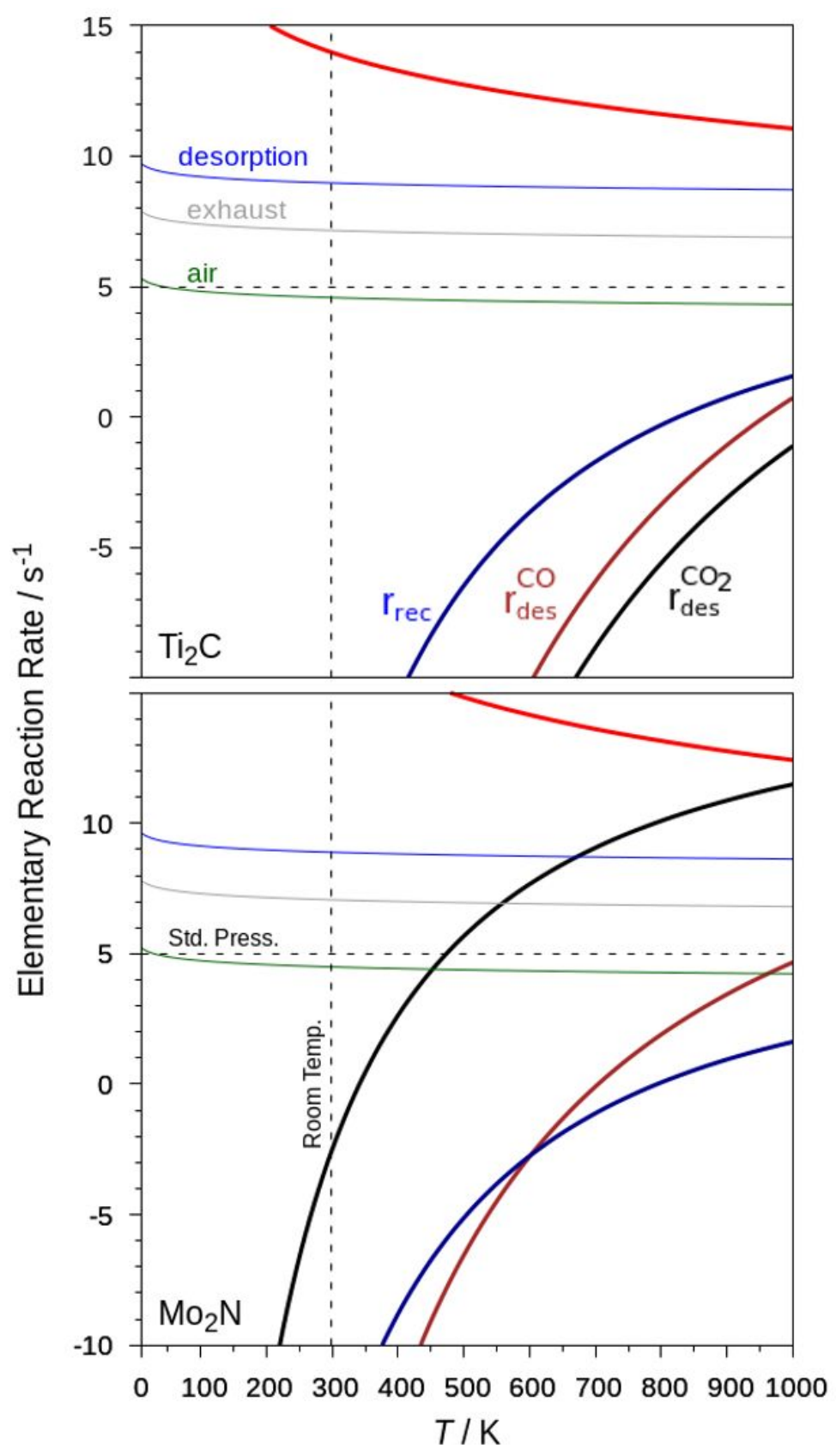




\section{S6. Kinetic phase diagrams}

For a molecular gas $-\mathrm{CO}_{2}$ or $\mathrm{CO}-$, its adsorption on a MXene surface competes with its desorption. Thus, one can envisage a dynamic equilibrium situation in which the adsorption rate equals the desorption rate. Thus, by equaling $r_{\mathrm{ads}}=r_{\mathrm{des}}$, as shown in Eqs. S5 and S6, one can isolate the gas pressure, either $p_{\mathrm{CO}_{2}}$ or $p_{\mathrm{CO}}$, as a function of temperature, $T$. By plotting the list of $p$ and $T$ conditions at which the equality is met, one can create a phase diagram based on the kinetics of adsorption/desorption, so that the gas would be preferentially adsorbed at higher pressures and lower temperatures than the equilibrium line, and, consequently, preferentially desorbed at lower pressures and higher temperatures. The rates evaluation in Figure S6 determine that, within the explored conditions regions, the $\mathrm{CO}_{2} *$ is preferably dissociated rather than staying intact, and so will be until $\mathrm{CO}^{*}$ desorbs, thus the region of $\mathrm{CO}^{*}+\mathrm{O}^{*}$ reaching the $\mathrm{CO}$ desorption line. This info is used to build up the kinetic phase diagrams for carbide- and nitride-based MXenes in Figures S7 and S8, respectively, revealing the regions of influence. 
Figure S7. Kinetic phase diagrams for carbide-based $\mathrm{M}_{2} \mathrm{C}$ MXenes as a function of $p_{\mathrm{CO}_{2}}$ and $p_{\mathrm{CO}}$ partial pressures, both in logarithmic scale of its values in $\mathrm{Pa}$, and temperature, $T$, in $\mathrm{K}$. Standard pressure of $10^{5} \mathrm{~Pa}$, and temperature of 298.15 $\mathrm{K}$ are shown as dashed lines. Regions of $\mathrm{CO}^{*}+\mathrm{O}^{*}$ (grey) and $\mathrm{O}^{*}$ (blue) preferences are shown shaded. Curved lines denote operando conditions where adsorption/desorption rate constants are at equilibrium, either for $\mathrm{CO}_{2}$ (black) or $\mathrm{CO}$ (red).

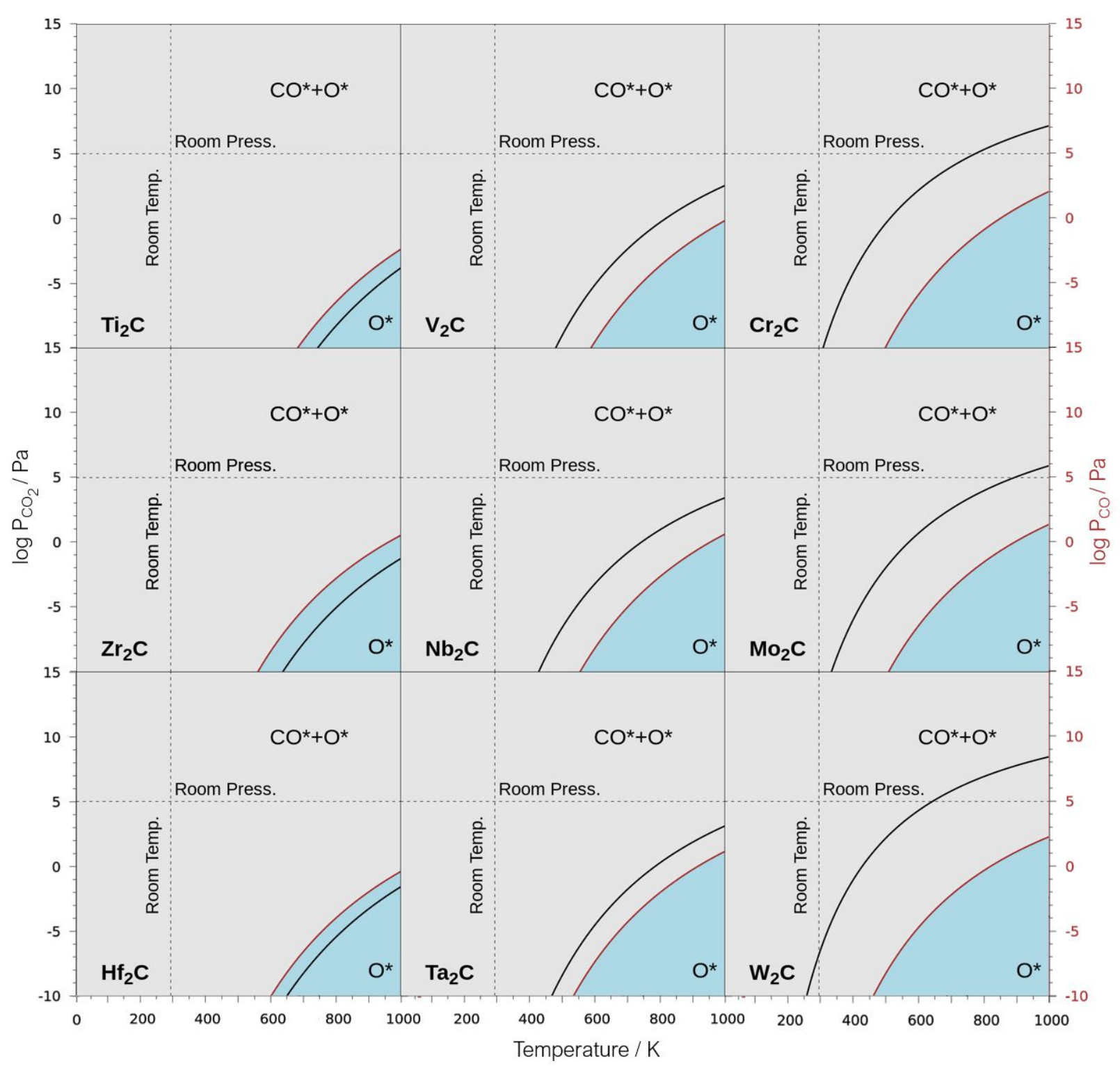


Figure S8 Kinetic phase diagrams for nitride-based $\mathrm{M}_{2} \mathrm{~N}$ MXenes as a function of $p_{\mathrm{CO}_{2}}$ and $p_{C O}$ partial pressures, both in logarithmic scale of its values in $\mathrm{Pa}$, and temperature, $T$, in $\mathrm{K}$. Standard pressure of $10^{5} \mathrm{~Pa}$, and temperature of $298.15 \mathrm{~K}$ are shown as dashed lines. Regions of $\mathrm{CO}^{*}+\mathrm{O}^{*}$ (grey) and $\mathrm{O}^{*}$ (blue) preferences are shown shaded. Curved lines denote operando conditions where adsorption/desorption rate constants are at equilibrium, either for $\mathrm{CO}_{2}$ (black) or $\mathrm{CO}$ (red).

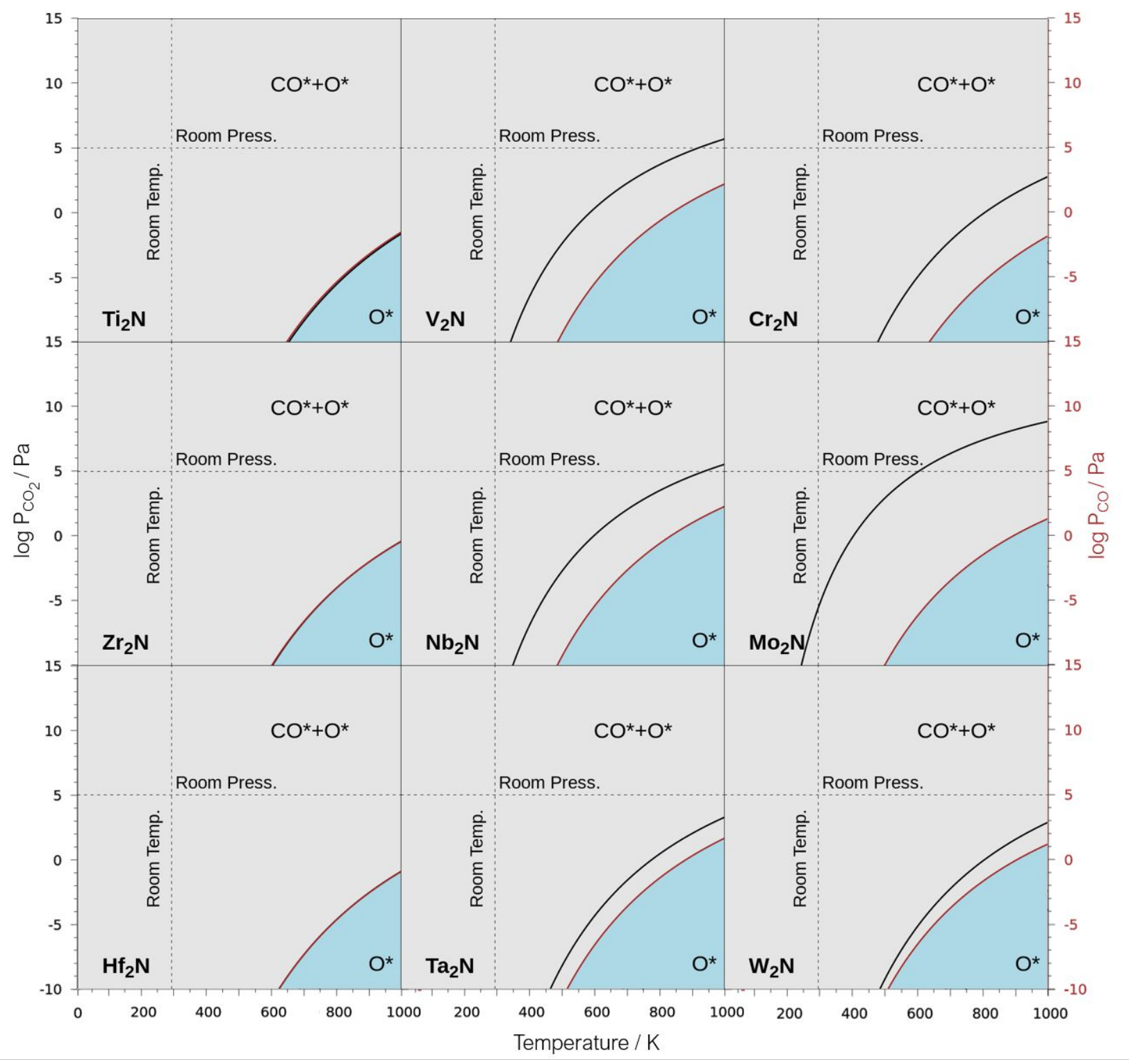




\section{S7. Oxygen coverage effects}

The above reaction evaluation yields, regardless of the studied MXene, to an eventual poisoning of the (0001) surfaces by $\mathrm{O}$ adatoms. Here we evaluated the adsorption and reaction capabilities of the explored MXene surfaces at a much higher $\mathrm{O}$ adatom coverage, $\theta_{\mathrm{O}}$, compared to the pristine situation of $\theta_{\mathrm{O}}=0$ monolayer (ML), discussed above. Models have been constructed for $\mathrm{Ti}_{2} \mathrm{C}$ and $\mathrm{Mo}_{2} \mathrm{~N}$ limiting cases, as the rest of the MXenes family will feature an activity framed within these two fringe cases. To this end, first, a full O-coverage situation, $\theta_{\mathrm{O}}=1 \mathrm{ML}$, has been evaluated by placing an $\mathrm{O}$ atom over each $\mathrm{O}_{\mathrm{m}}$ or $\mathrm{O}_{\mathrm{x}}$ site on $\mathrm{Ti}_{2} \mathrm{C}$ and $\mathrm{Mo}_{2} \mathrm{~N}$, respectively, in accordance to the $\mathrm{O}$ atomic adsorption preference shown in Table $\mathrm{S} 1$. For both $\mathrm{Ti}_{2} \mathrm{C}$ and $\mathrm{Mo}_{2} \mathrm{~N}$, the $\mathrm{CO}_{2}$ adsorption energies —including ZPE - are -0.18 and $-0.19 \mathrm{eV}$, respectively, with the linear $\mathrm{CO}_{2}$ molecule materially non-specifically physisorbed at 3.42 and $3.16 \AA$, respectively, away from the $\mathrm{Ti}_{2} \mathrm{CO}_{2}$ and $\mathrm{Mo}_{2} \mathrm{NO}_{2}$ MXene surfaces, see Figure S9. This is a clear indication of a weak interaction, mostly governed by dispersive forces, a point that makes CCS impracticable, as only achievable at ultrahigh $\mathrm{CO}_{2}$ partial pressures of $\mathrm{ca} .10^{9} \mathrm{~Pa}$ when working at room temperature, or cryogenic temperatures of $\sim 100 \mathrm{~K}$ when working with a $p_{\mathrm{CO}_{2}}$ of $10^{5} \mathrm{~Pa}$.

Furthermore, we investigated the $\mathrm{CO}_{2}$ adsorption and dissociation on a nearly fully $\mathrm{O}$ covered situation. To this end, $\mathrm{Ti}_{2} \mathrm{C}$ and $\mathrm{Mo}_{2} \mathrm{~N}$ were modeled at a $\theta_{\mathrm{O}}=0.67 \mathrm{ML}$, a coverage previously employed to assess the dry reforming of methane. ${ }^{21}$ In such a situation, there are still patches of the MXene surface capable of capturing $\mathrm{CO}_{2}$, with computed $E_{\text {ads }}$ - including ZPE — of 1.29 and $-0.85 \mathrm{eV}$ for $\mathrm{Ti}_{2} \mathrm{C}$ and $\mathrm{Mo}_{2} \mathrm{~N}$ MXenes, respectively, see Figure $\mathrm{S} 10$. In such cases, the $\mathrm{CO}_{2}$ still gets chemisorbed and activated on the surface, while displaying still very small dissociation energy barriers of 0.06 and $0.17 \mathrm{eV}$ for $\mathrm{Ti}_{2} \mathrm{C}$ and $\mathrm{Mo}_{2} \mathrm{~N}$, respectively. Finally, the final state may be viewed as $C O$ adsorbed on a surface model with $\theta_{\mathrm{O}}=0.78 \mathrm{ML}$, and with $\mathrm{CO} E_{a d s}$ values of -0.29 and $-1.75 \mathrm{eV}$ for $\mathrm{Ti}_{2} \mathrm{C}$ and $\mathrm{Mo}_{2} \mathrm{~N}$, respectively. Notice that even if O-coverage reduces both $\mathrm{CO}_{2}$ and $\mathrm{CO}$ adsorption energies, they are still strong enough to enable $\mathrm{CCS}, \mathrm{CCU}$, and the release of $\mathrm{CO}$ at certain operando conditions, as shown in the manuscript. Indeed, these results reinforce the two distinct operando modes, either with a continuous release of the as-generated $\mathrm{CO}$ in the case of $\mathrm{Ti}_{2} \mathrm{C}$, or the saturation of the surface by $\mathrm{CO}^{*}$ and $\mathrm{O}^{*}$ species after dosing $\mathrm{CO}_{2}$, followed by a release of $\mathrm{CO}$ by annealing and generating vacuum conditions for $\mathrm{Mo}_{2} \mathrm{~N}$. In both cases, though, an eventual regeneration of the MXene catalyst is required to remove the remaining $\mathrm{O}$ adatoms. 
Figure S9 Top (top) and side (bottom) views of $\mathrm{CO}_{2}$ physisorbed on fully O-covered $\mathrm{Ti}_{2} \mathrm{C}$ and $\mathrm{Mo}_{2} \mathrm{~N}$ MXenes - here $\mathrm{Ti}_{2} \mathrm{CO}_{2}$ and $\mathrm{Mo}_{2} \mathrm{NO}_{2}$, respectively-. Color code as in Figure $\mathrm{S} 2$.

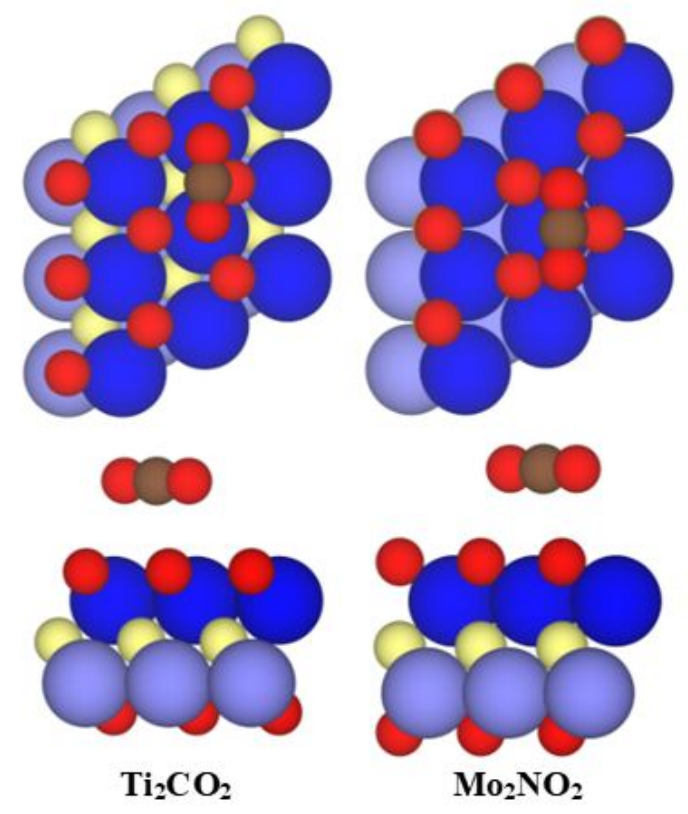


Figure S10 Reaction energy profiles for $\mathrm{CO}_{2}$ dissociation on $\mathrm{Ti}_{2} \mathrm{C}$ (upper panel) and $\mathrm{Mo}_{2} \mathrm{~N}$ (lower panel) basal surfaces with an $\mathrm{O}$ adatom coverage, $\theta_{\mathrm{O}}$, of $0.67 \mathrm{ML}$. $\mathrm{CO}_{2}$ adsorption and $\mathrm{CO}$ desorption steps are shown as initial and final stages. Images show the top (top) and side (bottom) views of the adsorbed $\mathrm{CO}_{2}$ dissociation into adsorbed $\mathrm{O}$ and $\mathrm{CO}$, including the initial $\mathrm{CO} 2 *$ state, the final $\mathrm{CO}^{*}+\mathrm{O}^{*}$ final state, and the dissociation TS, TS ${ }^{\text {dis }}$. Color code as in Figure S2.

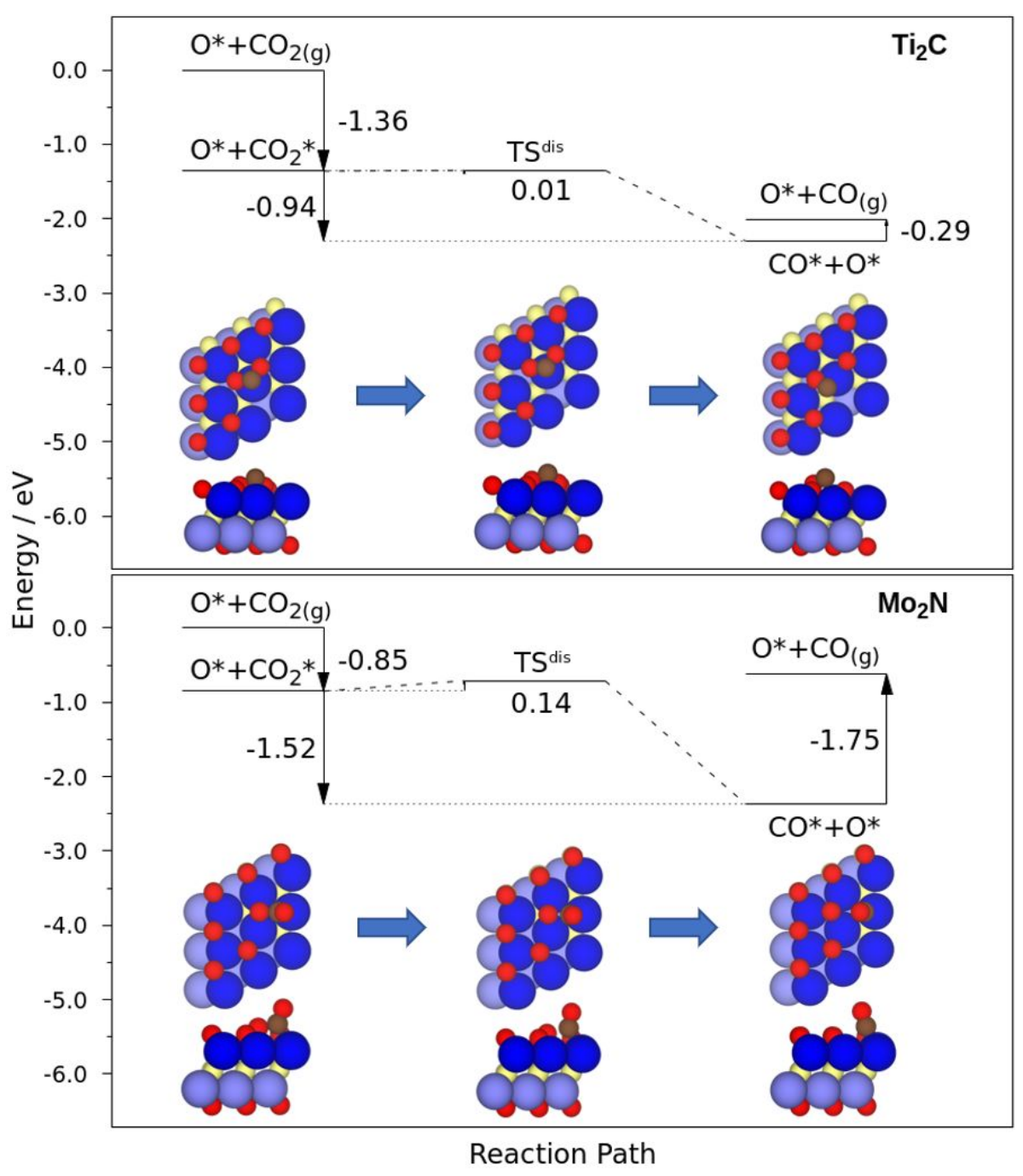




\section{References}

(1) Morales-García, Á.; Fernández-Fernández, A.; Viñes, F.; Illas, F. $\mathrm{CO}_{2}$ Abatement Using TwoDimensional MXenes Carbides. J. Mater. Chem. A 2018, 6, 3381-3385.

(2) Morales-Salvador, R.; Morales-García, Á.; Viñes, F.; Illas, F. Two-Dimensional Nitrides as Highly Potential Candidates for $\mathrm{CO}_{2}$ Capture and Activation. Phys. Chem. Chem. Phys. 2018, 20, 17117-17124.

(3) Prats, H.; McAloone, H.; Viñes, F.; Illas, F. Ultra-High Selectivity Biogas Upgrading Through Porous MXenes. J. Mater. Chem. A 2020, 8, 12296-12300.

(4) Hammer, B.; Nørskov, J.K. Electronic Factors Determining the Reactivity of Metal Surfaces. Surf. Sci. 1995, 343, 211-220.

(5) Henkelman, G.; Arnaldsson, A.; Jónsson, H. A Fast and Robust Algorithm for Bader Decomposition of Charge Density. Comput. Mater. Sci. 2006, 36, 354-360.

(6) Jin, D.; Johnson, L. R.; Raman, A. S.; Ming, X.; Gao, Y.; Du, F.; Wei, Y.; Chen, G.; Vojvodic, A.; Gogotsi, Y.; Meng, X. Computational Screening of 2D Ordered Double Transition-Metal Carbides (MXenes) as Electrocatalysts for Hydrogen Evolution Reaction. J. Phys. Chem. C 2020, 124,10584-10592.

(7) Vega, L.; Martínez, B.; Viñes, F.; Illas, F. Robustness of Surface Activity Electronic StructureBased Descriptors of Transition Metals. Phys. Chem. Chem. Phys. 2018, 20, 20548-20554.

(8) Morales-García, Á.; Calle-Vallejo, F.; Illas F. MXenes: New Horizons in Catalysis. ACS Catal. 2020, 10, 13487-13503.

(9) Nitoń, P.; Żywociński, A.; Fiałkowski, A.; Hołyst, R. A. "Nano-Windmill” Driven by a Flux of Water Vapour: a Comparison to the Rotating ATPase. Nanoscale 2013, 5, 9732-9738.

(10) Burghaus, U. Surface Science Perspective of Carbon Dioxide Chemistry - Adsorption Kinetics and Dynamics of $\mathrm{CO}_{2}$ on Selected Model Surfaces. Catal. Today 2009, 148, 212-220.

(11) Kunkel, C.; Viñes, F.; Illas, F. Transition Metal Carbides as Novel Materials for $\mathrm{CO}_{2}$ Capture, Storage, and Activation. Energy Environ. Sci. 2016, 9, 141-144.

(12) Takahashi, T.; Sutherland, S.; Kozyr, A. Global Ocean Surface Water Partial Pressure of $\mathrm{CO}_{2}$ Database: Measurements Performed During 1957-2014, Environmental Science Division, Oak Ridge National Laboratory, 2015.

(13) D’Alessandro, D.M.; Smit, B.; Long, J.R. Carbon Dioxide Capture: Prospects for New Materials. Angew. Chem. Int. Ed. 2010, 49, 6058-6082.

(14) Boot-Handford, M.E.; Abanades, J.C; Anthony, E.J.; Blunt, M.J.; Brandani, S.; MacDowell, N.; Fernández, J. R.; Ferrari, M.-C.; Gross, R.; Hallett, J. P.; Haszeldine, R. S.; Heptonstall, P.; 
Lyngfelt, A.; Makuch, Z.; Mangano, E.; Porter, R. T. J.; Pourkashanian, M.; Rochelle, G. T.; Shah, N.; Yao, J. G.; Fennell, P. S. Carbon Capture and Storage Update. Energy Environ. Sci. 2014, 7, 130-189.

(15) Esposito, E.; Dellamuzia, L.; Moretti, U.; Fuoco, A.; Giorno, L.; Jansen, J. C. Simultaneous Production of Biomethane and Food Grade $\mathrm{CO}_{2}$ from Biogas: an Industrial Case Study. Energy Environ. Sci. 2019, 12, 281-289.

(16) Atkins, P. W.; De Paula, J. Atkins' Physical chemistry, Oxford University Press: New York, 2006.

(17) Burghaus, U.; Conrad, H. A Molecular Beam Relaxation Spectroscopy Study of CO adsorption on $\operatorname{Ag}(110)$ and $\operatorname{Pt}(111)$. Surf. Sci. 1995, 331-333, 116-120.

(18) Kunat, M.; Boas, C.; Becker, T.; Burghaus, U.; Wöll, C. Adsoprtion Dynamics of CO on $\mathrm{Cu}(110)$ : a Molecular Beam Study. Surf. Sci. 2001, 474, 114-128.

(19) Kneitz, S.; Gemeinhardt, J.; Koschel, H.; Held, G., Steinrück, H.-P. Energy and Temperature Dependent Sticking Coefficients of CO on Ultrathin Copper Layers on Ru(001). Surf. Sci. 1999, 433-435, 27-31.

(20) Kneitz, S.; Gemeinhardt, J.; Steinrück, H.-P. A Molecular Beam Study of the Adsorption Dynamics of $\mathrm{CO}$ on $\mathrm{Ru}(0001), \mathrm{Cu}(111)$, and a Pseudomorphic $\mathrm{Cu}$ Monolayer on $\mathrm{Ru}(0001)$. Surf. Sci. 1999, 440, 307-320.

(21) Kurlov, A.; Deeva, E. B.; Abdala, P. M.; Lebedev, D.; Tsoukalou, A.; Comas-Vives, A.; Fedorov, A.; Müller, C. R. Exploiting Two-Dimensional Morphology of Molybdenum Oxycarbide to Enable Efficient Catalytic Dry Reforming of Methane. Nat. Commun. 2020, 11, 4920. 